\title{
Editorial
}

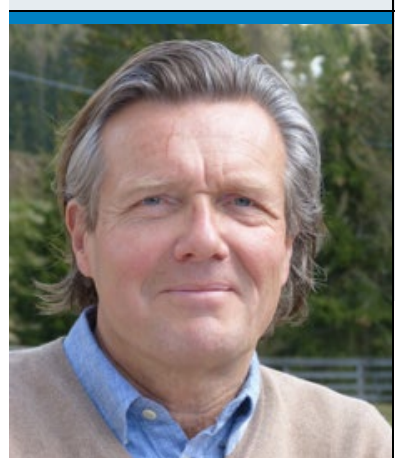

„Noch vor einem Jahr freute man sich bei den gesetzlichen

Krankenkassen über erhebliche Überschüsse, nun werden

plötzlich massive Defizite erwartet. Da drängen sich einige

Fragen auf."

Prof. Dr. med Gerhard Grevers

Chefredaktion

\section{Sag mir, wo die Gelder sind}

$\mathrm{K}$ urz vor dem Jahreswechsel werden überall im Lande Versicherungsträger aktiv, um mit angeblich günstigeren Tarifen neue Kunden anzulocken. Wir kennen das von der Auto-, aber auch der privaten Krankenversicherung.

Ganz anders bei den Gesetzlichen; hier überschlugen sich seit Anfang Dezember die Hiobsbotschaften. Eine Kasse nach der anderen kündigt Beitragserhöhungen an, da für 2016 bereits jetzt ein Defizit von 14 Milliarden antizipiert wird (220 Milliarden prospektiven Ausgaben stehen angeblich 206 Milliarden Einnahmen gegenüber). Erfahrungsgemäß werden solche Schätzungen am Ende des Tages ja nochmal ordentlich nach oben korrigiert. Wie kann das sein? Anfang 2015 lagen die Finanzreserven der Gesetzlichen doch noch bei 28 Milliarden Euro. Da hat sich wohl der eine oder andere gefragt, wohin mit den ganzen lästigen Überschüssen. Wir kennen diesen sportlichen Ansatz im Umgang mit dem Geld anderer ja seit Langem aus der Steuerpolitik. Entsprechend wollten sich wohl auch die Kassen nicht lumpen lassen - an vorderster Front, wie üblich, die AOK mit ihren vollmundigen Werbesprüchen („meine AOK kann das"). Und wie die kann ... Zunächst einmal wurde der Etat des Medizinischen Dienstes der Krankenkassen aufgestockt; die wiederum nutzten die Geldspritze dann allen Ernstes, um den Nutzen von IGeL überprüfen zu lassen, die die Kassen - wie wir wissen - ja ohnehin nicht bezahlen, statt - was viel naheliegender wäre - zu untersuchen, wo zu viel ausgegeben wird (da fallen mir jetzt spontan gleichmal die Vorstandsgehälter ein!). Doch damit nicht genug, auch beim Thema Vorsorge kann man ordentlich Geld ausgeben, dachten sich wohl die Entscheidungsträger und ließen es dann so richtig krachen. Neben den üblichen Verdächtigen auch hier wieder die AOK an vorderster Front beim Verteilen von Versichertengeldern: Gemeinsam mit einem Veranstalter von Urlaubsreisen bietet sie (Originalton) „Wohlfühlreisen zur Prävention" an. Die TKK will da natürlich nicht zurückstehen und kooperiert mit einem Hotel auf Ischia in Sachen „Medical Wellness“. So sieht "gesunder" Wettbewerb im deutschen Krankenversicherungswesen heute aus.

Aber liebe Leser, es geht natürlich weiter ... Wer sich nämlich lieber heimatnah verwöhnen lassen möchte, wird selbstverständlich auch hierzulande großzügig bedient. Auf Kosten der Beitragszahler natürlich, denen im Gegenzug Heil- und Hilfsmittel gestrichen werden; in einschlägigen Internetforen feixen AOK-Mitglieder mittlerweile über das „Fitnessstudio auf Lau“. Abgerechnet werde direkt über die Versichertenkarte, alle Leistungen würden gezahlt, einschließlich Sauna und „Getränkeflat"; die AOK versteht sich halt als „die Gesundheitskasse“ (Werbeslogan), frei nach dem Motto: Was kümmern uns die Kranken.

Wer eher auf Open-Air-Rock als auf Fitness steht, darf natürlich nicht benachteiligt werden: „steifer Nacken in Wacken?", mit diesem originellen Schüttelreim berichtet das DÄ 33/34 auf Seite 1 über weitere fragwürdige Praktiken der GKV. Hintergrund diesmal: Auf Krankenkassenkosten gönnten sich Versicherte (bei einem Rockkonzert in Wacken, Schleswig-Holstein) eine Nackenmassage nach "Headbangen“ (rhythmische Kopfbewegungen zur Musik). Zweiklassenmedizin halt, nur andersrum. „Mit Gesundheit wirbt es sich halt schöner als mit Krankheit" schreibt die Frankfurter Allgemeine Sonntagszeitung in einem Leitartikel mit dem Titel „Yogakurs statt Asthmamittel“, denn das Thema begeistert naheliegenderweise zwischenzeitlich auch die Laienpresse.

Mittlerweile gibt es aber wenigstens auch zu den Sparmaßnahmen der GKV Onlineforen, in denen sich die Leidtragenden der „Wellnesspolitik“ zu Wort melden. Seit Sommer vergangenen Jahres befasst sich nun notgedrungen sogar der Gesundheitsausschuss des Bundestages mit dem Thema. Sie brauchen halt immer etwas länger, unsere Volksvertreter.

Sie sehen, auch im Neuen Jahr geht es lustig weiter.

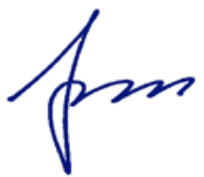

